\title{
Response to anthracnose infection for a subset of Ethiopian sorghum germplasm ${ }^{1}$
}

\author{
John E. Erpelding ${ }^{2}$ and Louis K. Prom ${ }^{3}$
}

J. Agric. Univ. P.R. 93(3-4):195-206 (2009)

\begin{abstract}
Forty-two accessions were randomly selected from the Ethiopian sorghum collection maintained by the USDA-ARS National Plant Germplasm System and were evaluated for anthracnose disease response during the 2004 dry and wet growing seasons in Isabela, Puerto Rico. A resistant response was observed for 20 accessions, with 13 accessions susceptible to the disease for the two growing seasons. This finding would suggest that Ethiopia would be an important source of anthracnose-resistant germplasm for sorghum improvement. Nine accessions showed variation for infection response within and between growing seasons. These accessions also showed low infection severity. Greater infection severity was observed during the dry growing season for the susceptible accessions; however, variation for mean infection severity for these accessions was not significantly different for the two seasons. Approximately $\mathbf{8 0} \%$ of the accessions showed a similar disease response across the two growing seasons. This percentage would suggest that large scale evaluations could be conducted throughout the year in Puerto Rico to screen the more than 7,000 Ethiopian sorghum accessions in the collection for the identification of anthracnose-resistant germplasm.
\end{abstract}

Key words: Colletotrichum sublineolum, disease evaluation, genetic resources, host plant resistance, Sorghum bicolor

\section{RESUMEN}

\section{Respuesta de germoplasma de sorgo de Etiopía a la antracnosis}

Se seleccionaron al azar 42 accesiones de la colección de sorgo de Etiopía, la cual se mantiene en el Sistema Nacional de Germoplama de Plantas del Servicio de Investigación Agrícola del Departamento de Agricultura de los Estados Unidos (USDA-ARS, NGPS, por sus siglas en inglés). Se evaluó la respuesta de estas accesiones a la antracnosis durante las épocas de lluvia y de sequía en Isabela, Puerto Rico, en el 2004. Se observó resistencia a la enfermedad en $\mathbf{2 0}$ accesiones, mientras trece accesiones resultaron susceptibles a la enfermedad en ambas épocas. Estos resultados indican que la colección de sorgo de Etiopía es una fuente importante de germoplasma resistente a la antracnosis para utilizarse en el mejoramiento del sorgo. Nueve accesiones mostraron una variación en la respuesta a la infección dentro y fuera de las épocas de crecimiento. Estas accesiones también mostraron una baja severidad de infección. Las accesiones susceptibles a la en-

${ }^{1}$ Manuscript submitted to Editorial Board 18 September 2008.

${ }^{2}$ Research Geneticist, corresponding author, USDA-ARS, Tropical Agriculture Research Station, 2200 P.A. Campos Ave., Suite 201, Mayagüez, PR 00680-5470.

${ }^{3}$ Research Plant Pathologist, USDA-ARS, Southern Plains Agriculture Research Center, 2765 F \& B Road, College Station, TX 77845. 


\begin{abstract}
fermedad mostraron una infección mayor durante la época de sequía; sin embargo, la variación promedio de infección de estas accesiones no fue significativamente diferente para las dos épocas. Aproximadamente $80 \%$ de las accesiones mostraron una respuesta similar a la enfermedad a través de las dos épocas de crecimiento. Estos resultados indican que en Puerto Rico se pueden llevar a cabo evaluaciones en alta escala a través de todo el año para examinar más de 7,000 accesiones de sorgo de la colección e identificar germoplasma resistente a la antracnosis.
\end{abstract}

Palabras clave: Colletotrichum sublineolum, evaluación de enfermedades, recursos genéticos, resistencia, Sorghum bicolor

\title{
INTRODUCTION
}

Anthracnose is one of the major economically important diseases in sorghum (Sorghum bicolor (L.) Moench) production. The pathogen responsible for sorghum anthracnose is Colletotrichum sublineolum P. Henn., Kabát \& Bubák (Crouch et al., 2006). The disease was first identified in Togo, West Africa, in 1902 (Thakur and Mathur, 2000). Sorghum anthracnose occurs worldwide but is more prevalent in tropical and subtropical regions, where warm humid climatic conditions enhance its development. All above-ground tissues of the sorghum plant can be infected by the pathogen, with foliar disease being more commonly observed (Thakur and Mathur, 2000). Symptoms generally appear 30 to 40 days after seedling emergence, but infection can occur at every stage of plant development. Characteristic disease symptoms on susceptible cultivars appear as circular, elliptical, or elongated lesions. Sporulation of the fungus results in the development of asexual fruiting bodies (acervuli) that appear as black spots in the center of the lesions. Under favorable environmental conditions, lesions will coalesce on susceptible cultivars. The disease can rapidly spread, infecting most of the leaf area, all of which can result in leaf senescence, premature defoliation, or plant death.

Foliar anthracnose infection can significantly reduce sorghum grain production. Grain yield losses from 41 to $67 \%$ were observed for an experimental evaluation conducted in Mali, West Africa (Thomas et al., 1996). Ali et al. (1987) reported a 30\% reduction in grain yield for a susceptible sorghum cultivar inoculated with an aggressive isolate of the pathogen. Grain yield losses were typically associated with a reduction in grain weight.

The incidence and severity of sorghum anthracnose infection can be reduced through the use of fungicides and cultural practices, but the use of resistant cultivars provides a more economical and environmentally safe approach to stabilizing production. Resistant sorghum hybrids are available in the United States and recommended for production areas where anthracnose is prevalent. Effective sources of anthracnose resistance have been incorporated into sorghum cultivars, 
but variation and evolution in the pathogen population has influenced the long-term durability of single sources of resistance (Rosewich et al., 1998; Thakur and Mathur, 2000). Also, numerous studies have indicated that pathotype variation for anthracnose is extensive within and between global regions (Ali and Warren, 1987; Cardwell et al., 1989; Pande et al., 1991; Guthrie et al., 1992; Rosewich et al., 1998; Marley et al., 2001; Valério et al., 2005); thus, identification of new sources of resistance is needed for sorghum improvement.

Sorghum was domesticated in northeastern Africa. Ethiopia is considered one of the major centers of diversity (Stemler et al., 1977). To conserve this genetic diversity, more than 7,000 sorghum accessions have been collected from Ethiopia and are maintained by the USDAARS National Plant Germplasm System. The Ethiopian collection may also be a source of host plant resistance to anthracnose. Therefore, 42 sorghum accessions were randomly selected among those in the Ethiopian collection for evaluating variation in anthracnose disease response. In order to determine the feasibility of conducting large-scale evaluations throughout the year to screen a greater number of accessions from the Ethiopian collection, these accessions were selected for assessing whether or not seasonal climatic variation would significantly influence infection response.

\section{MATERIALS AND METHODS}

The Ethiopian sorghum collection maintained by the USDA-ARS National Plant Germplasm System in Griffin, Georgia, is composed of 7,229 accessions (GRIN, 2007). For the identification of resistant germplasm lines a subset of 42 accessions was randomly selected to evaluate anthracnose disease response. Three accessions from Mali, West Africa (PI 609151, PI 609251, and PI 609746) were included as anthracnosesusceptible control genotypes (Erpelding and Prom, 2004). The breeding line BTx623 (PI 564163) was susceptible to anthracnose pathotypes present in the continental United States and Puerto Rico, and it was included as a susceptible control (Erpelding et al., 2005). The anthracnose-susceptible genotype Sureño (PI 561472), a sorghum cultivar developed in Honduras, was also a control (Meckenstock et al., 1993). Breeding lines BTx378, RTx2536, and SC748-6 were included as anthracnose-resistant controls that also confer resistance to pathotypes present in the continental United States.

The anthracnose evaluation was conducted at the USDA-ARS Tropical Agriculture Research Station in Isabela, Puerto Rico, during the 2004 dry and wet growing seasons to determine infection response for contrasting environmental conditions. Table 1 presents weather data 
TABLE 1.-Climatic conditions during the dry and wet growing seasons in 2004 for the anthracnose evaluation of the 42 Ethiopian sorghum accessions conducted in Isabela, Puerto Rico.

\begin{tabular}{lcc}
\hline Weather Variable $^{1}$ & Dry Season & Wet Season \\
\hline Total Rainfall $(\mathrm{mm})$ & 189.5 & 376.7 \\
Number of days with rain & 33 & 33 \\
Average Temperature $\left({ }^{\circ} \mathrm{C}\right)$ & 23.8 & 25.4 \\
Minimum Temperature $\left({ }^{\circ} \mathrm{C}\right)$ & 16.6 & 20.2 \\
Maximum Temperature $\left({ }^{\circ} \mathrm{C}\right)$ & 29.6 & 32.1 \\
Average Relative Humidity $(\%)$ & 80.3 & 82.6 \\
Minimum Relative Humidity $(\%)$ & 40.1 & 45.9 \\
Maximum Relative Humidity $(\%)$ & 97.7 & 96.0 \\
\hline
\end{tabular}

${ }^{1}$ Weather data were summarized from the period after disease inoculation until the final anthracnose evaluation was conducted. For the dry season evaluation, plants were inoculated 28 February 2004; the final disease evaluation was conducted 9 May 2004. For the wet season evaluation, plants were inoculated 30 August 2004, and the final evaluation was 28 October 2004. For data summation, weather data were collected at 5-minute intervals for rainfall and at 10-minute intervals for temperature and relative humidity.

for the two growing seasons. The anthracnose evaluation conducted during the dry season was planted 22 January 2004, and the final disease reading was conducted 9 May 2004. For the wet season evaluation accessions were planted 2 August 2004; the evaluation was completed 28 October 2004. The accessions were planted in single rows, $1.8 \mathrm{~m}$ in length with $0.9-\mathrm{m}$ row spacing. We used a partially balanced lattice design with three replications. The experimental fields were surrounded by border rows of anthracnose-susceptible genotypes. Fertilizer of 15-510 formulation was applied at a rate of $560 \mathrm{~kg} / \mathrm{ha}$ at planting. Chlorpyrifos granular insecticide (Dow AgroSciences, Indianapolis, IN) ${ }^{4}$ was applied at a rate of $8 \mathrm{~kg} / \mathrm{ha}$ at planting to prevent seed loss from fire ants. Supplemental irrigation was applied by overhead sprinklers. For the dry season evaluation, irrigation was applied five times before anthracnose inoculation; no irrigation was applied after inoculation. Rainfall occurred the day after inoculation for the dry season evaluation. For the wet growing season, supplemental irrigation was applied after planting and two times before inoculation; after inoculation there was a single application. Weeds were controlled with mechanical tillage and hand hoeing.

${ }^{4}$ Mention of company names, trade names or commercial products in this publication is solely for the purpose of providing specific information and does not imply recommendations or endorsement by the U.S. Department of Agriculture or the University of Puerto Rico. 
At the Isabela research site, anthracnose-infected leaf samples were collected at random before the evaluation to investigate the pathotypes present. The preparation of anthracnose cultures, inoculation, and disease evaluation were as described by Erpelding and Prom (2006). Lesions were excised from infected leaf samples, surface sterilized, placed in half strength potato-dextrose agar ( $1 / 2 \mathrm{PDA})$ media, and incubated at room temperature for approximately five days. Small portions of the developing fungal cultures were then transferred on to fresh $1 / 2$ PDA media and cultured at room temperature for seven days. Sorghum seed was soaked in water overnight, rinsed, placed in glass bottles, and autoclaved. The seven-day-old cultures were used to inoculate the sorghum seed, and the fungus was cultured at room temperature for five days until the seed was completely colonized. Field inoculations were conducted by placing approximately 10 anthracnose-colonized seeds into the leaf whorl of each plant, with approximately $90 \%$ of the plants in a row being inoculated. Plants were inoculated 37 days after planting in the dry season and 28 days after planting in the wet season. For the experiment conducted in the dry season, the anthracnose infection response was evaluated at 38,51 , and 69 days after inoculation. Disease development was delayed during the dry season by approximately seven days of windy weather, which prevented dew formation. Therefore, to compensate for the slow development of the disease, we delayed the evaluations. During the wet season, anthracnose infection response was assessed at $12,33,43$, and 58 days after inoculation. The response to anthracnose infection was evaluated by using a 1 to 5 rating scale based on disease response observed on inoculated leaves and disease progression on non-inoculated leaves (Erpelding and Prom, 2004). Ratings 1 and 2 correspond to a resistant response, and ratings 3,4 , and 5 correspond to a moderately susceptible, susceptible, and highly susceptible response, respectively. Plants rated as 1 show no disease symptoms. Plants showing reddening of inoculated leaves and no lesion development with acervuli are rated as 2 . Susceptible plants showing the development of acervuli in the center of chlorotic lesions are rated as 3. Plants rated as 4 show the development of acervuli in the center of necrotic lesions, with infection spreading to non-inoculated leaf tissue. Highly susceptible plants rated as 5 show coalescence of lesions with abundant acervuli resulting in leaf senescence, with infection observed on most leaves, including the flag leaf. For evaluating quantitative responses to anthracnose infection, we estimated the percentage of infected leaf area during the final evaluation for the susceptible accessions. The percentage of infected leaf area or disease severity was based on a visual rating of the susceptible plants within a row. Statistical analysis of the data was based on the disease severity from the final 
rating. The Statistix software package (Analytical Software, Tallahassee, FL) was used to conduct an analysis of variance. Mean comparisons were conducted by using the Least Significant Difference method (LSD), with a rejection value for alpha of 0.05 .

\section{RESULTS}

Table 2 presents the anthracnose disease response data for the 42 Ethiopian sorghum accessions. A resistant response to anthracnose infection was observed for 24 accessions during the dry season evaluation, whereas 15 accessions showed a susceptible response. Three accessions showed variation for infection response across replications during the dry season. Five of the 15 susceptible accessions showed a susceptible response across replications 38 days after inoculation. Eleven accessions showed a susceptible response across replications 51 days after inoculation (data not shown). For the anthracnose evaluation conducted during the wet season, 23 accessions showed a resistant response. A susceptible response was observed for 16 accessions. Variation for infection response across replications was observed for three accessions. The hypersensitive response, reddening of inoculated leaves, was more pronounced during the wet season; an evaluation was conducted 12 days after inoculation. Nearly all the accessions showed some senescence of leaf margins and tips from infection. Six of the 16 susceptible accessions showed a susceptible response across replications 12 days after inoculation, with variation in susceptibility between replications observed for six additional accessions (data not shown). Thirteen accessions were rated as susceptible 33 days after inoculation. During the wet season, 43 days after inoculation, all 16 susceptible accessions showed a susceptible response across replications (data not shown).

Thirty-three accessions showed no variation for disease response between the dry and wet growing seasons. A resistant response was observed for 20 accessions, and a susceptible response was observed for 13 accessions (Table 2). Two accessions (PI 267614 and PI 330094) that showed a resistant response in the dry season were susceptible in the wet season. One accession (PI 330877) rated as susceptible in the dry season showed a resistant response for the wet season evaluation. Three accessions that showed variation in disease response across replications in the dry season showed either a resistant or susceptible disease response across replications in the wet season. Similarly, three accessions that showed variation in disease response during the wet season showed either a resistant or susceptible disease response across replications in the dry season. 
TABLE 2.-Anthracnose disease response for 42 Ethiopian sorghum germplasm accessions and eight control genotypes inoculated with Colletotrichum sublineolum and evaluated under field conditions in Isabela, Puerto Rico, during the dry and wet growing seasons in 2004.

\begin{tabular}{|c|c|c|c|c|}
\hline \multirow[b]{2}{*}{ Accession $^{1}$} & \multicolumn{2}{|c|}{ Dry Season } & \multicolumn{2}{|c|}{ Wet Season } \\
\hline & Disease Rating ${ }^{2}$ & Disease Severity ${ }^{3}$ & Disease Rating & Disease severity \\
\hline PI 151303 & 2 & $0 a^{4}$ & 2 & $0 \mathrm{a}$ \\
\hline PI 248238 & 2 & $0 \mathrm{a}$ & 2 & $0 \mathrm{a}$ \\
\hline PI 267580 & 2 & $0 \mathrm{a}$ & 2 & $0 \mathrm{a}$ \\
\hline PI 267643 & 2 & $0 \mathrm{a}$ & 2 & $0 \mathrm{a}$ \\
\hline PI 276769 & 2 & $0 \mathrm{a}$ & 2 & $0 \mathrm{a}$ \\
\hline PI 276787 & 2 & $0 \mathrm{a}$ & 2 & $0 \mathrm{a}$ \\
\hline PI 276788 & 2 & $0 \mathrm{a}$ & 2 & $0 \mathrm{a}$ \\
\hline PI 276816 & 2 & $0 \mathrm{a}$ & 2 & $0 \mathrm{a}$ \\
\hline PI 276817 & 2 & $0 \mathrm{a}$ & 2 & $0 \mathrm{a}$ \\
\hline PI 276819 & 2 & $0 \mathrm{a}$ & 2 & $0 \mathrm{a}$ \\
\hline PI 276820 & 2 & $0 \mathrm{a}$ & 2 & $0 \mathrm{a}$ \\
\hline PI 276830 & 2 & $0 \mathrm{a}$ & 2 & $0 \mathrm{a}$ \\
\hline PI 276840 & 2 & $0 \mathrm{a}$ & 2 & $0 \mathrm{a}$ \\
\hline PI 276850 & 2 & $0 \mathrm{a}$ & 2 & $0 \mathrm{a}$ \\
\hline PI 329707 & 2 & $0 \mathrm{a}$ & 2 & $0 \mathrm{a}$ \\
\hline PI 329719 & 2 & $0 \mathrm{a}$ & 2 & $0 \mathrm{a}$ \\
\hline PI 330070 & 2 & $0 \mathrm{a}$ & 2 & $0 \mathrm{a}$ \\
\hline PI 330174 & 2 & $0 \mathrm{a}$ & 2 & $0 \mathrm{a}$ \\
\hline PI 563509 & 2 & $0 \mathrm{a}$ & 2 & $0 \mathrm{a}$ \\
\hline NSL 365745 & 2 & $0 \mathrm{a}$ & 2 & $0 \mathrm{a}$ \\
\hline PI 148097 & 2 & $0 \mathrm{a}$ & $2 \backslash 2 \backslash 4$ & $<1 \mathrm{a}$ \\
\hline PI 276791 & 2 & $0 \mathrm{a}$ & $2 \backslash 2 \backslash 4$ & $3 a b$ \\
\hline PI 267614 & 2 & $0 \mathrm{a}$ & 4 & $13 \mathrm{~b}$ \\
\hline PI 330094 & 2 & $0 \mathrm{a}$ & 4 & $2 \mathrm{a}$ \\
\hline PI 147926 & $2 \backslash 2 \backslash 4$ & $3 \mathrm{a}$ & 2 & $0 \mathrm{a}$ \\
\hline PI 276806 & $2 \backslash 2 \backslash 4$ & $3 a$ & 2 & $0 \mathrm{a}$ \\
\hline PI 149831 & $2 \backslash 4 \backslash 5$ & $20 \mathrm{~b}-\mathrm{e}$ & 4 & $4 \mathrm{ab}$ \\
\hline PI 330877 & 4 & $7 \mathrm{ab}$ & 2 & $0 \mathrm{a}$ \\
\hline PI 276785 & 4 & $12 \mathrm{a}-\mathrm{c}$ & $2 \backslash 2 \backslash 4$ & $<1 \mathrm{a}$ \\
\hline PI 147829 & 4 & $38 \mathrm{~g}$ & 4 & $30 \mathrm{~cd}$ \\
\hline
\end{tabular}

${ }^{1}$ Plant introduction numbers for the accessions included in the evaluation (GRIN, 2007). The 42 accessions are listed based on disease response from resistant (rating $=2$ ) to susceptible (rating $=4$ or 5). Resistant controls (BTx378, SC748-6 and RTx2536). Susceptible controls (PI 561472, PI 564163, PI 609151, PI 609251 and PI 609746).

${ }^{2}$ Disease ratings are based on a 1 to 5 scale (Erpelding and Prom, 2006). Resistant plants are rated as 2 , susceptible plants rated as 4 , and highly susceptible plants rated as 5 . Rows with a single value indicate no variation for disease response across replications within an experiment. An accession with more than one disease rating indicates variation across replications within an experiment for infection response and data are presented for the three replications.

${ }^{3}$ Mean disease severity for the three replications in a growing season based on a visual estimate of the percentage of infected leaf area for the susceptible plants within a row. $(<1)$ $=$ mean infected leaf area for the three replications was less than $1 \%$.

${ }^{4}$ Means followed by the same letter are not significantly different $\left(\operatorname{LSD}_{0.05}\right)$. 
TABLE 2.-(Continued) Anthracnose disease response for 42 Ethiopian sorghum germplasm accessions and eight control genotypes inoculated with Colletotrichum sublineolum and evaluated under field conditions in Isabela, Puerto Rico, during the dry and wet growing seasons in 2004.

\begin{tabular}{|c|c|c|c|c|}
\hline \multirow[b]{2}{*}{ Accession $^{1}$} & \multicolumn{2}{|c|}{ Dry Season } & \multicolumn{2}{|c|}{ Wet Season } \\
\hline & Disease Rating ${ }^{2}$ & Disease Severity ${ }^{3}$ & Disease Rating & Disease severity \\
\hline PI 147919 & 4 & $18 \mathrm{~b}-\mathrm{d}^{4}$ & 4 & $37 \mathrm{de}$ \\
\hline PI 148104 & 4 & $40 \mathrm{gh}$ & 4 & $43 \mathrm{e}$ \\
\hline PI 329902 & 4 & $9 a b$ & 4 & $2 \mathrm{a}$ \\
\hline PI 148089 & $4 \backslash 4 \backslash 5$ & $30 \mathrm{~d}-\mathrm{g}$ & 4 & $40 \mathrm{de}$ \\
\hline PI 148105 & $4 \backslash 4 \backslash 5$ & $23 \mathrm{c}-\mathrm{f}$ & 4 & $30 \mathrm{ed}$ \\
\hline PI 330872 & $4 \backslash 5 \backslash 5$ & $32 \mathrm{~d}-\mathrm{g}$ & 4 & $4 a b$ \\
\hline PI 257599 & 5 & $80 \mathrm{ij}$ & 4 & $13 \mathrm{~b}$ \\
\hline PI 330869 & 5 & $53 \mathrm{~h}$ & 4 & $35 \mathrm{c}-\mathrm{e}$ \\
\hline PI 276842 & 5 & $77 \mathrm{ij}$ & $4 \backslash 4 \backslash 5$ & 37 de \\
\hline PI 147934 & 5 & $43 \mathrm{gh}$ & 5 & $83 \mathrm{~g}$ \\
\hline PI 152589 & 5 & $90 \mathrm{j}$ & 5 & $60 \mathrm{f}$ \\
\hline PI 257598 & 5 & $82 \mathrm{ij}$ & 5 & $60 \mathrm{f}$ \\
\hline SC748-6 & 2 & $0 \mathrm{a}$ & 2 & $0 \mathrm{a}$ \\
\hline ВТх378 & 2 & $0 \mathrm{a}$ & $2 \backslash 2 \backslash 4$ & $<1 \mathrm{a}$ \\
\hline RTx2536 & 2 & $0 \mathrm{a}$ & $2 \backslash 4 \backslash 5$ & $3 \mathrm{ab}$ \\
\hline PI 561472 & 5 & $37 \mathrm{fg}$ & 5 & $25 \mathrm{c}$ \\
\hline PI 564163 & $4 \backslash 5 \backslash 5$ & $33 \mathrm{e}-\mathrm{g}$ & 5 & $73 \mathrm{~g}$ \\
\hline PI 609151 & 5 & $70 \mathrm{i}$ & 5 & $60 \mathrm{f}$ \\
\hline PI 609251 & 5 & $90 \mathrm{j}$ & 5 & $80 \mathrm{~g}$ \\
\hline PI 609746 & 5 & $83 \mathrm{ij}$ & 5 & $77 \mathrm{~g}$ \\
\hline
\end{tabular}

${ }^{1}$ Plant introduction numbers for the accessions included in the evaluation (GRIN, 2007). The 42 accessions are listed based on disease response from resistant (rating $=2$ ) to susceptible (rating $=4$ or 5). Resistant controls (BTx378, SC748-6 and RTx2536). Susceptible controls (PI 561472, PI 564163, PI 609151, PI 609251 and PI 609746).

${ }^{2}$ Disease ratings are based on a 1 to 5 scale (Erpelding and Prom, 2006). Resistant plants are rated as 2 , susceptible plants rated as 4 , and highly susceptible plants rated as 5 . Rows with a single value indicate no variation for disease response across replications within an experiment. An accession with more than one disease rating indicates variation across replications within an experiment for infection response and data are presented for the three replications.

${ }^{3}$ Mean disease severity for the three replications in a growing season based on a visual estimate of the percentage of infected leaf area for the susceptible plants within a row. $(<1)$ $=$ mean infected leaf area for the three replications was less than $1 \%$.

${ }^{4}$ Means followed by the same letter are not significantly different $\left(\operatorname{LSD}_{0.05}\right)$.

Disease severity, as determined by the percentage of infected leaf area, was estimated during the final disease assessment for the anthracnose-susceptible accessions (Table 2). Highly significant differences were observed among accessions for disease severity. Greater disease severity was observed for the susceptible accessions during the dry growing season. The mean infected leaf area for the 13 susceptible accessions during the dry growing season was $48 \%$, compared to a mean 
of $36 \%$ infected leaf area for the wet season. The mean infected leaf area was similar between growing seasons for five of the 13 susceptible accessions, but no consistent pattern was observed between the growing seasons. In addition, the difference in mean infected leaf area was not significant between growing seasons. The mean infected leaf area was generally low for the accessions that showed variation in disease response between growing seasons and across replications within a growing season.

The anthracnose disease response for the resistant and susceptible control genotypes included in the evaluation was similar within and between experiments, with the exception of the response of BTx378 and RTx2536 (Table 2). Variation in disease response was observed across replications for these two sorghum genotypes during the wet growing season, but the percentage of infected leaf area was low, and not all plants in the row showed a susceptible response. The five anthracnosesusceptible controls included in the evaluation were rated as highly susceptible, and mean infected leaf area was generally similar between growing seasons. During the dry season, mean infected leaf area was $65 \%$, compared to a mean of $63 \%$ during the wet season evaluation for the five susceptible controls.

\section{DISCUSSION}

Nearly $50 \%$ of the 42 Ethiopian sorghum accessions showed a resistant response to anthracnose pathotypes in Isabela. This finding would suggest that the Ethiopian sorghum collection is a valuable source for anthracnose-resistant germplasm. Ethiopia is considered a center of diversity for sorghum, and a large germplasm collection has been assembled to conserve the genetic diversity associated with this region. Sorghum anthracnose occurs in Ethiopia; therefore, disease pressure may favor the development and selection of host plant resistance. Additionally, the sorghum germplasm collection from Ethiopia may also contain genetic diversity for anthracnose disease resistance. Twenty accessions were rated as resistant and showed no variation for infection response under epidemic disease conditions nor under highly variable climatic conditions. These accessions may provide additional sources of anthracnose resistance for sorghum improvement, but evaluation at other locations will be essential. Resistant accessions identified in Puerto Rico have frequently shown resistance to anthracnose pathotypes in Texas and Georgia (Erpelding and Prom, 2004; Erpelding and Prom, 2006).

Two accessions (NSL 365745 and PI 148097) were identified from the evaluation and have been used as control genotypes in additional 
evaluations. These two resistant accessions show diversity in anthracnose disease response phenotypes. NSL 365745 typically shows the formation of small red spots on inoculated leaves. In contrast, PI 148097 shows nearly complete reddening of inoculated leaves with extensive senescence of leaf margins. Acervuli development on inoculated leaves has also been observed for PI 148097 at a low frequency.

Field evaluations for disease response are significantly influenced by climatic conditions. Warm temperatures, excessive rainfall, high relative humidity, and prolonged dew periods are environmental conditions that will contribute to anthracnose disease development (Pande et al., 1994; Thakur and Mathur, 2000; Ngugi et al., 2002). Studies conducted in Burkina Faso and Mali, West Africa, have indicated that anthracnose disease severity was higher at the wetter locations (Néya and Le Normand, 1998; Hess et al., 2002). Erpelding and Prom (2004) also observed variation in anthracnose disease response between the wet and dry growing seasons in Isabela, where the wet season was associated with greater disease severity. Although nearly twice as much rainfall was received during the wet growing season than during the dry season (Table 1), greater infection severity was observed during the dry season for the Ethiopian germplasm evaluation. The influence of rainfall on infection response may have been reduced during the wet season since rainfall occurred on a similar number of days during the two growing seasons. These results would indicate that rainfall may not be a limiting factor influencing infection response for evaluations conducted in Isabela; thus, other climatic variables should be considered for anthracnose evaluations. For instance, the cooler temperatures during the dry season could have prolonged the dew period, which may have enhanced disease development. The duration of rainfall also varied between growing seasons. During the wet season, intense rain storms generally occurred in the afternoon, whereas rain storms typically occurred throughout the day during the dry season. Not all accessions showed greater disease severity during the dry season evaluation, thus suggesting that a genotypic-by-environment interaction also influenced infection response. This environmental interaction may have contributed to the variation in disease response observed for the resistant controls BTx378 and RTx2536 during the wet season. Additionally, these results would suggest that evaluations conducted throughout growing seasons with diverse climatic conditions may be more useful for the identification of anthracnose-resistant germplasm accessions. Variation in anthracnose pathotypes may also have contributed to the variation observed in disease response within and between experiments; if so, then the 20 accessions rated as resistant may confer resistance to multiple pathotypes of the disease. 
Even though infection severity varied between growing seasons, nearly $80 \%$ of the accessions showed a similar disease response across the two growing seasons. This finding would suggest that climatic conditions in Isabela are favorable for anthracnose disease development. These results would indicate that large-scale evaluations could be conducted throughout the year to identify resistant germplasm in the Ethiopian sorghum collection. Resistant germplasm could then be further evaluated over multiple growing seasons or at different locations to confirm resistance and to select germplasm for sorghum improvement.

\section{LITERATURE CITED}

Ali, M. E. K. and H. L. Warren, 1987. Physiological races of Colletotrichum graminicola on sorghum. Plant Dis. 71:402-404.

Ali, M. E. K., H. L. Warren and R. X. Latin, 1987. Relationship between anthracnose leaf blight and losses in grain yield of sorghum. Plant Dis. 71:803-806.

Cardwell, K. F., P. R. Hepperly and R. A. Frederiksen, 1989. Pathotypes of Colletotrichum graminicola and seed transmission of sorghum anthracnose. Plant Dis. 73:255-257.

Crouch, J. A., B. B. Clarke and B. I. Hillman, 2006. Unraveling evolutionary relationships among the divergent lineages of Colletotrichum causing anthracnose disease in turfgrass and corn. Phytopathology 96:46-60.

Erpelding, J. E. and L. K. Prom, 2004. Evaluation of Malian sorghum germplasm for resistance against anthracnose. Plant Pathol. J. 3:65-71.

Erpelding, J. E. and L. K. Prom, 2006. Variation for anthracnose resistance within the sorghum germplasm collection from Mozambique, Africa. Plant Pathol. J. 5:28-34.

Erpelding, J. E., L. K. Prom and W. L. Rooney, 2005. Variation in anthracnose resistance within the Sudanese sorghum germplasm collection. Plant Genet. Resour: Newsl. 141:11-14.

GRIN, 2007. USDA-ARS National Genetic Resources Program. Germplasm Resources Information Network (GRIN). Online database. National Germplasm Resources Laboratory, Beltsville, MD, USA. 17 February 2007. http:/www.ars-grin.gov/.

Guthrie, P. A. I., C. W. Magill, R. A. Frederiksen and G. N. Odvody, 1992. Random amplified polymorphic DNA markers: a system for identifying and differentiating isolates of Colletotrichum graminicola. Phytopathology 82:832-835.

Hess, D. E., R. Bandyopadhyay and I. Sissoko, 2002. Pattern analysis of sorghum genotype $\times$ environment interaction for leaf, panicle, and grain anthracnose in Mali. Plant Dis. 86:1374-1382.

Marley, P. S., R. P. Thakur and O. Ajayi, 2001. Variation among foliar isolates of Colletotrichum sublineolum of sorghum in Nigeria. Field Crops Res. 69:133-142.

Meckenstock, D. H., F. Gomez, D. T. Rosenow and V. Guiragossian, 1993. Registration of Sureño sorghum. Crop Sci. 33:213.

Néya, A. and M. Le Normand, 1998. Responses of sorghum genotypes to leaf anthracnose (Colletotrichum graminicola) under field conditions in Burkina Faso. Crop Prot. 17:47-53.

Ngugi, H. K., S. B. King, G. O. Abayo and Y. V. R. Reddy, 2002. Prevalence, incidence, and severity of sorghum diseases in western Kenya. Plant Dis. 86:65-70.

Pande, S., L. K. Mughogho, R. Bandyopadhyay and R. I. Karunakar, 1991. Variation in pathogenicity and cultural characteristics of sorghum isolates of Colletotrichum graminicola in India. Plant Dis. 75:778-783. 
Pande, S., R. P. Thakur, R. I. Karunakar, R. Bandyopadhyay and B. V. S. Reddy, 1994. Development of screening methods and identification of stable resistance to anthracnose in sorghum. Field Crops Res. 38:157-166.

Rosewich, U. L., R. E. Pettway, B. A. McDonald, R. R. Duncan and R. A. Frederiksen, 1998. Genetic structure and temporal dynamies of a Colletotrichum graminicola population in a sorghum disease nursery. Phytopathology 88:1087-1093.

Stemler, A. B. L., J. R. Harlan and J. M. J. de Wet, 1977. The sorghums of Ethiopia. Econ. Bot. 31:446-460.

Thakur, R. P. and K. Mathur, 2000. Anthracnose: pp 10-12, In: R. A. Frederiksen and G. N. Odvody (eds.), Compendium of Sorghum Diseases. The American Phytopathological Society, St. Paul, MN.

Thomas, M. D., I. Sissoko and M. Sacko, 1996. Development of leaf anthracnose and its effect on yield and grain weight of sorghum in West Africa. Plant Dis. 80:151-153.

Valério, H. M., M. A. Resende, R. C. B. Weikert-Oliveira and C. R. Casela, 2005. Virulence and molecular diversity in Colletotrichum graminicola from Brazil. Mycopathologia 159:449-459. 